\title{
The possessive investment in guns: towards a material, social, and racial analysis of guns
}

\author{
Brandon Hunter-Pazzara ${ }^{1 凶}$
}

\begin{abstract}
In the midst of public attention to the question of racial gun violence both at the hands of vigilantes and police, this essay draws from anthropological theory on object-human relationships to reframe our understanding of racial gun violence. Following Appadurai's $(1986,2015)$ attention to the "social lives" of objects and the way that objects function as both "median and materiality," this essay argues that the demand for self-defense has altered the meaning of firearms and produced a system in which racial gun violence is normalized. Formed in three parts, the first develops a theoretical framework for thinking about the role of objects, in this case guns, in the production of social relationships. Doing so, this essay argues, allows us to take objects seriously as actors that work to produce moments of racial gun violence, as well as understand how these patterns of gun violence are the result of the mass production, distribution, and racialized marketing of the gun for the purpose of self-defense. In the second section, I utilize this framework to trace the legal, marketing, and engineering shifts that have resulted in the expansion of concealed carry laws, the development of a highly racialized marketing strategy that ties gun ownership to self-defense, and the production of smaller and more powerful pistols which now dominate the gun market. This new era of guns in American life builds from a longer history in which the gun remains central to the maintenance of the American racial order. Yet, the gun in this sense is not simply a signifier of race, but as this essay maintains, is both a material component shaping the bodily practices and cognitive capacities of gunowners, and a billion-dollar industry that has lobbied successfully to make guns more accessible and to make their use, for whites, less accountable under the law. In the final section, I undertake a rereading of the murder of Trayvon Martin, focusing on George Zimmerman's murder weapon and the role it played both in the killing of Martin, and in sparing Zimmerman from conviction. By focusing on the role guns play in instances of racial violence and inequality, this essay demonstrates how new materialist scholarship can chart new pathways for understanding this important and timely issue.
\end{abstract}

\footnotetext{
${ }^{1}$ Princeton University, Princeton, USA. ${ }^{凶}$ email: bh11@princeton.edu
} 


\section{Introduction}

n May of 2016, nearly 4 years after the murder of Trayvon Martin and 3 years after the controversial trial that acquitted George Zimmerman, Zimmerman successfully auctioned the weapon he used to slay Martin. Reports eventually confirmed that the gun sold for $\$ 250,000$ to a woman looking to purchase the object as a present for her son. Commenting on the depravity of the sale, Leonard Pitts Jr. connected it to the gruesome tradition of whites taking the body parts of lynched African Americans as souvenirs (Pitts Jr, 2016). "Trayon Martin," Pitts Jr wrote, "was thing-ified" and "his murder commodified" by the sale of the weapon. Where a culture of whiteness drained Martin of his humanity, it was that same culture that transformed the gun from an object into an icon of self-defense and freedom-for those who enjoy white privilege. It simultaneously represented the terrifying power of whiteness and yet was indicative of a gun culture rooted in a racialized fear of people of color.

In response to tragedies like Martin's murder, the racial bias of police and white gun owners is under increasing scrutiny from the public. These two groups, while distinct in certain ways, remain entangled by the use of their firearm and the social permission both groups inherit from the founding of the United States to use their weapons against people of color. The entrenched and systemic nature of this violence tends to be overshadowed by scrutinizing the individual conscious or unconscious racial bias. From this perspective, these shootings are the result of racial bias and it is this bias that structures and determines behavior. Focusing on intentionality leaves unquestioned the systemic ways in which guns find themselves in the hands of whites, how their use causes harm to people of color, and the way that harm is justified as self-defense. In this essay, I turn towards an analysis of the gun, exploring its "social life" and attending to the material ways guns produce social relations. A focus on the objects that cause racial harm builds on critical studies of race that emphasize the systemic nature of racism and racial privilege but does so by taking into account the material nature of that privilege and the distinct role of objects in these relationships. Following the work of Latour (2005) and Bennett (2010) I want to take guns seriously, treating them as coconstitutive of racial violence, or in Saldanha's (2006) terms, as part of the "immanent process" in which bodies, objects, places, and events intermingle to produce racial gun violence. The gun, this paper contends, is not merely an inert object used by racist officers and white gunowners but is an active component that structures the relations that lead to racial gun violence in the United States.

For the purpose of this essay, I use the term racial gun violence in a narrow way to describe the use of guns by police officers and whites against people of color in the context of self-defense. Certainly, racial gun violence includes more than claims of selfdefense to justify one's use of a firearm against people of color. Mass shootings in which the assailant specifically targets people of color, as happened in an El Paso Wal-Mart in 2019, is obviously another form of racial gun violence. Further, the persistent neglect of gun violence in poor communities of color constitutes a systemic form of racism rooted in sentiments that naturalize the existence of gun violence in these communities. This essay contends that at the heart of these various instances of gun violence is the weapon itself, which is not simply a neutral tool used to cause harm, but an object shaped by and shaping of race, racism, and racial violence.

Attending to the role of objects in society is a central theme in the work of anthropologist Arjun Appadurai and I draw from two conceptual developments in his scholarship; the first relates to the understanding of the social processes that produce and distribute objects and allow for particular social relations to come into being, that is, objects' "social lives" (Appadurai, 1986) The second, is a newer concept that builds on the previous idea and emphasizes the agentive nature of objects in shaping, constraining, and advancing human action-objects conceived as both "mediants" and materiality (Appadurai, 2015).

Newer gun scholarship takes up the first method of analysis, focusing on the way gun makers market, advertise, and distribute their products (Haag, 2016; Saylor et al., 2004; Yamane et al., 2009). These studies lend insight into the social construction of the American gun market by highlighting the imagery, tropes, and messaging gunmakers and gun rights organizations produce to encourage the purchasing of firearms and expand the access of firearms through the loosening of gun regulations. A robust scholarship exists documenting the way gun advertising attempts to appeal to white, male consumers, yet less studied is the way the privileges of gun ownership accrue mostly to whites and the disproportionate effect gun control measures have on people of color (cf. Light, 2017; Murphy, 2018).

Aside from a handful of psychological studies on the way gun ownership shapes cognitive perception (Witt and Brockmole, 2012; Swanson et al., 2015), American gun scholarship has yet to attend to the materiality of guns, that is, the way the gun specifically mediates social interactions and the ways the material qualities of a gun affect both gunowners and those threatened, harmed, or murdered by guns (cf. Shapira and Simon, 2018). This point may seem obvious, but the reality is that as gun demand has shifted to self-defense, gunmakers increasingly design firearms that more efficiently and effectively cause harm (Squires, 2019). Despite public focus on assault rifles, handguns cause the majority of gun deaths in the United States, with newer designs that result in smaller, deadlier, and more accurate weapons. It is the contention of this paper that such engineering feats cannot be understood without appreciating the role of white supremacy in shaping the demand for self-defense.

The gun, of course, is not the only source of racial violence in the United States, but between police and vigilantes alike, gun violence claims the most lives. Gun violence by whites against people of color (particularly men of color) is one source of harm, but as Parham-Payne (2014) observes, gun violence disproportionately affects people of color (especially youth). Media coverage of "black on black" gun violence often naturalizes the violence, accepting it as a cultural pathology rather than a systemic failure requiring political solutions. A systemic account of racial gun violence helps us understand the way race neutral policy can produce racist outcomes (Bonilla-Silva, 2006). This is not to say that whites, or even white men, do not experience harm from gun ownership and loose gun regulations. As Metzl (2019) compellingly demonstrates, whites acutely experience the negative health effects of gun ownership, a feature of their "cruel attachments" (Borneman, 2015) to contemporary conservative dogma. This essay's narrower focus on gun violence against people of color through a critical analysis of self-defense calls attention to the harmful effects of guns, but also the ways in which the rights and privileges of gun ownership remain largely unavailable to communities of color (Murphy, 2018). The systemic denial of those rights is linked to a racialized discourse of gun ownership for the purpose of self-defense-a discourse that makes such violence both possible and justified.

The relationship between guns and racism traces back to the colonial period of the United States. From laws that prohibited African Americans and indigenous people from possessing weapons (Cramer, 1994), to the role of the gun in various campaigns of conquest. Its presence across America's history must be understated as a tool of colonization and sovereignty (Smith, 2015; Light, 2017; Squires, 1996) that extends into the present and 
shapes contemporary forms of racial control and violence. This essay focuses on the shift in gun demand for the purpose of selfdefense and traces three distinct, yet entangled, ways self-defense has been mediated to produce the material effect of racial gun violence in the United States: (1) the racialized marketing and advertising of guns for personal self-defense, (2) the role of law in extending gun rights to whites and gun possession penalties to people of color, and the (3) material changes to gun design that emphasize smaller, deadlier handguns for personal carry and selfdefense use.

I organize this essay into three sections. In the first section I set up the theoretical framing, bringing Appadurai's conceptual work on objects in conversation with critical approaches to race. In the next section, I deploy this framework to explore the three ways in which the logic of self-defense transformed guns as racialized objects, and in the final section, I offer a reading of the Trayvon Martin murder that focuses on Zimmerman's gun as a way of highlighting the tragedy's enchainment within a broader system of social relations that follow the growth of self-defense. While Zimmerman's intentions are for others to decide, this essay's systemic focus on guns reveals Martin's murder and Zimmerman's acquittal as a logical outcome of the culture of self-defense in the United States.

\section{Guns as objects}

This essay draws from two theories developed by Arjun Appadurai for the study of objects. The first, is the notion that objects possess "social lives" (1986), or more specifically that by following "the things themselves" we might understand how "their meanings are inscribed in their forms, their uses, their trajectories" (p. 5). Building on Georg Simmel's idea that value is produced through exchange, rather than from objects themselves, Appadurai's critical intervention is to note that within the production and exchange of objects are complex social relations and points of contestation. For Appadurai, this produces a politics which he defines as "the broad set of agreements concerning what is desirable, what a reasonable exchange of sacrifices comprises, and who is permitted to exercise what kind of effective demand in what circumstances," as well as the, "tendency of commodities to breach these frameworks" (p. 57). Exchange, thus, makes objects social and it is through a close examination of that sociality that we understand how the value of objects is conceived and the points of contestation that allows meaning and significance of that value to change over time.

Appadurai's approach attempts to move past the idea that objects are inert and mute, that at best they simply signify individual preferences. Instead, this theory asks that we consider our desire for objects as a social construction conceived through social relations between different social groups. Gun scholarship has followed this theoretical line by focusing on gun advertising and the way the gun business manipulates our desire for guns (Haag, 2016). Yet, Appadurai's claim is not that behind these interventions lurks the real value of an object, but that an object's value is always socially constructed first and that dominant social meanings are always in a state of contestation as a result of their production, consumption, exchange, and use. Guns, therefore, are not just objects but contain political and social value that can signify masculinity (Saylor et al., 2004; O'Neill, 2007), garner respect (Fagan and Wilkinson, 1998), and for some gunowners their possession constitutes both an act of freedom and the means by which freedom is secured (LaPierre, 2003). Guns, in essence, are priceless, that is, their value extends beyond mere market relations.

While Appadurai does not specifically mention race, the social life of things offers a method for exploring the way various social groups, including various racial groups in particular societies, construe and negotiate the value of objects. The gun is well suited to this line of inquiry because of its regulation through the course of American history. Colonial American gun regulations prohibited African slaves and sometimes indigenous people from possessing firearms, some colonies required white men to carry a firearm for the purpose of community defense, and yet the gun trade with indigenous groups had profound implications on indigenous politics and war making (Silverman, 2016). In our current moment, gun regulations disproportionately affect people of color, precluding many from taking advantage of expanded gun rights (Newton, 2017). The key point is that the social lives of guns are many, and are both shaped by, and shaping of, the politics of race.

Appadurai's second concept in the study of objects is the dual concepts of mediant and materiality (2015), which comes as a response to a larger set of concerns with the political and ethical implications of new materialist theory. Under new materialist theory, objects are more than just inert things used by humans to create the social, but instead ought to be understood as agentive components that shape the social in similar capacity to human actors. Under this framing, the ontological field between human and objects is "flattened," "de-centering" humans as the principle drivers of any particular phenomenon. Objects simultaneously enable and constrain our action, a point that is seemingly obvious and yet profound to the extent Western theories of agency traditionally privilege humans as the sole driver of social change. In response to this turn towards the agentive role of non-humans, scholars increasingly speculate on the political and ethical implications that follow. The "vibrancy" (Bennett, 2010) of matter and the presence of non-human actors are all well and good, but the issue becomes how these theoretical observations can be operationalized to enrich our understanding of social problems and build on political and ethical theorizations that rely on the centricity of human agency. For Appadurai (2015), the "normative paralysis," found in new materialist theory can be overcome by shifting our focus away from all "actants," to what Appadurai calls "mediants" (p. 222). Mediants are the "key movers" who through processes of mediation produce material outcomes, or materiality.

The idea builds on the work of Houtman and Meyer (2012) and their scholarship on the relationship between religion, media, and materiality. Their conclusion-that religion is a space of indeterminacy between the "thing" (Houtman and Meyer, 2012, p. 16) and the spiritual captures how the objective and immaterial function together, one mediating the other. Appadurai (2015) applies this observation to other sociocultural forces to ascertain the way objects become visible or invisible. Mediation is defined as "the operation or embodied practice" carried out by a mediant, while materiality is the "site of what mediation-as an embodied practice-reveals" (Appadurai, 2015, p. 224). Mediation and materiality are co-constitutive; each mediant requires a material form, built on a series of mediations grounded in a materiality. For example, the eye, as an organ with all its nerves and biological components, is a mediant that makes possible the act of seeing-a mediation, which in turn reveals the material world (colors, shapes, figures) which are then mediated through the cognitive processes and symbolic universe that allow us to make sense of what we see. What is revealed, however, is not just a matter of material affordances (whether the eye can see, or the hand can touch), but is also a political and ethical question to the extent that what becomes visible entails relations of power at work.

Mediants and materiality are assemblages of human and nonhuman actants. Racial gun violence is a material assemblage (guns, bullets, blood, black/brown person) that when mediated through the assemblage of personal self-defense renders the racial 
implications of this recurrent form of violence invisible. But selfdefense is also a material outcome of various intersecting mediations at work and I focus on three in this essay; the marketing and advertising of guns for self-defense, the laws that give selfdefense legal form, and the engineering and design advances in firearms and firearm accessories that create products specifically tailored for personal self-defense. These processes of mediation work in tandem, highlighting race (that is, making race material) in one instance by transforming the black/brown male into a threat to be defended against, while also rendering the racism of this violence invisible (to the state, to certain groups) through the laws that give self-defense legal form and efficacy.

The process that makes race visible, yet racist outcomes invisible, is a recurrent theme in critical race theory with important normative implications (McIntosh, 1988; Lipsitz, 1998; Ralph, 2014). Yet, these processes have largely been viewed as a relational outcome between human actors discursively distinguished by race and power-a process that is both agentive (how a group self-identifies and the construction of that identity) and interpellative (the way in which a group is made subject to racial discourses at particular moments). Materiality enters the picture but mostly as an acknowledgment that the discursive field of race is formed in part by the body and its phenotypic characteristics, that is, the biological and genetic processes that produce physical differences between people (Ahmed, 2007; Montoya, 2007). Bringing Appadurai's dual concept of mediation and materiality to critical race theory allows us to include the role of objects, or non-human actants, that constitute race. What we call racial harm can be understood as a material outcome of the way various processes of mediation unfold. The recognition of the repetition of these mediations refines our understanding of racism not as a set of static social relations, but rather, in Imani Perry's terms, as "a happening" (2011) rooted in unequal relations between humans and objects. For Appadurai, it is the capacity of humans as mediants with the "special responsibility" to recognize (or fail to recognize) that harm that allows his theory to bring political and ethical concerns into new materialist thinking (2015, p. 235).

These two ways of analyzing objects are complimentary. The social life of objects attends to the ways that objects derive social meaning through human created demand, a point that the concept of mediant and materiality furthers by considering how human and non-human actants shape that demand. In the next section I consider self-defense as a material outcome of three intersecting forms of mediation: the representation of self-defense through gun marketing and advertising; the legal form selfdefense takes through its mediation by law; and finally the way self-defense is mediated through gun and gun accessory engineering, which increasingly leads to deadlier and more concealable gun designs.

\section{Demanding self-defense}

"Demand," writes Appadurai (1986), "is a function of a variety of social practices and classifications" (p. 29) that go beyond thinking of demand as "a mysterious enumeration of human needs, a mechanical response to social manipulation," towards an understanding of demand as a socially constructed process that is neither wholly the result of "social manipulation" nor the simplistic "narrowing down of a universalist and voracious desire for objects" (p. 29). Put differently, demand for things emerges through social relations, but as things move across time and space that meaning is negotiated and transformed by various social actors. Bringing the insights of this first theory in line with Appadurai's second, we can understand demand as a material outcome in which the complex social relations described by Appadurai are treated as mediations carried out by human and non-human actants that form this demand. Yet demand, as Appadurai notes, "conceals two relationships between production and consumption" (p. 31). First, that demand is "determined by social and economic forces," and second, and perhaps more interesting, that demand "can manipulate, within limits, these social and economic forces" (Appadurai, 1986, p. 31). In this sense, demand is both a material outcome of various mediations at work and demand can act as a mediant producing other material effects.

One can follow the change in demand through the course of American history. During the colonial period the gun was an essential tool of protection against conflicts with indigenous nations, quelled slave rebellions and rural uprisings, facilitated westward expansion, and was later instrumental for American imperial conquest outside of the western hemisphere (DurbanOrtiz, 2018; Slotkin, 1985). In the New England colonies, towns required adult males to have a musket in possession at all times (Cornell and DeDino, 2004) while other colonies restricted Africans and indigenous people from possessing a weapon (Spitzer, 2017; Cramer, 1994; Light, 2017). The seeds of the modern gun industry formed during the Revolutionary War when George Washington settled on Springfield, Massachusetts as the site for the manufacture of weapons for the war effort. After American independence, industrialization found its way to New England and America's great gun manufacturers got their start (Osnos, 2016; Haag, 2016). Gun makers like Winchester, Colt, and Smith and Wesson would not simply innovate on gun design but work at all levels of society to shape gun demand (Haag, 2016).

The change in gun demand over time is the result of intersecting mediations between three distinct mediants: the processes by which guns are marketed and advertised; the laws that shape who can own guns and for what purpose; and the engineering, or technological, changes in gun design. Each of these mediants represents an assemblage of human and non-human actants who give shape and substance to gun demand. Such demand is neither static nor singular. Gun demand can be articulated as a demand to hunt, a demand for national self-defense, and in more recent times as a demand for personal self-defense. Yet, as Haag (2016) reminds us, demand for guns has always competed with other prevailing ideas of the gun taken up by gun owners as well as those who are opposed to guns. Competing demands mediate new kinds of demand in the process, as illustrated by gun rights advocates encouraging the purchase of weapons in response to fears their guns will be taken away or heavily regulated. By the 1960s, demographic changes in conjunction with the assassination of John F. Kennedy led to the decline in the popularity of guns and reignited a national conversation on gun control (Spitzer, 2005). Before the 1970s, bipartisan consensus held gun control as a sensible response to the obvious dangers posed by firearms. This line of thinking had come from the gun control efforts in the 1930s focused on reducing gun violence, but by the 1960s was influenced by the racial politics of the era as African Americans began to arm themselves and form community defense groups and radical political organizations in response to incessant police and white mob violence. One notable example occurred in 1967 when the Black Panther Party carried out an armed demonstration at the state capital building in Sacramento prompting then Republican governor Ronald Reagan to enact statewide gun control measures.

The political consensus around gun control began to fracture in the mid-1970s as demand for firearms became about selfdefense and gunowners began to form themselves into a distinct political constituency focused on expanding gun rights. The culture was racialized from its inception, as a reaction to the Civil Rights movement and a response to growing urban unrest and 
crime. Nixon's call for tough on crime policy combined with the start of The War on Drugs reflected racial dog whistles that formed part of the Republican Southern Strategy and paralleled cultural trends among white gun owners that stressed self-defense (Aistrup, 1996). These shifts were in step with changes taking place inside the National Rifle Association (NRA) that transformed the gun rights organization from a group concerned with gun safety and recreation into a political organization advocating for the protection and expansion of gun rights.

As a result, self-defense is now the principle motivator for gun purchases, an outcome of distinct changes in the way guns are advertised, designed, and regulated. Framing self-defense as a material outcome of these mediating forces is not to imply a top down relationship between demands for self-defense and those who make guns. The mediants that mediate self-defense are themselves assemblages of human and non-human actants connected in a networked order, rather than as a hierarchical relationship in which gun owners are the duped victims of the nefarious interests of gun merchants and pro-gun political leaders. This point becomes clear when one considers the narrow way in which self-defense is only defense against criminals and home invaders, an amorphous category of persons that insinuates class and racial anxieties (O'Brien et al., 2013) that have become more pronounced over the last several decades despite crime generally, and violent home invasions specifically, having fallen (Bureau of Justice Statistics, 2011). Self-defense must also be situated in the context of a gun market skewed by race as whites account for a disproportionate percentage of the 76 million American households who own at least one firearm (Morin, 2014). ${ }^{1}$ With some exceptions, American gun culture is unmistakably white and male, a consequence of the legacy of gun marketing (Haag, 2016), political messaging, and the marginalization of people of color from mainstream gun culture (Light, 2017).

Since gun, and gun accessories, are mass produced commodities, attending to the way they are advertised and marketed to consumers is key. Studies analyzing gun advertisements have examined print media and focused on the technical language used to describe guns (Saylor et al., 2004), the symbolic messaging involved in advertising (Hirschman, 2003), and the associated political messaging one finds in gun trade publications (Witkowski, 2013). Yamane et al. (2009) undertakes an examination of the last 100 years of gun advertisements in The American Rifleman, the official publication of the NRA. They note that by 2017 the magazine is "full of products specifically designed and sold for personal protection" (20), reflecting what they term "gun culture 2.0." As Carlson's (2015) study of what she calls "citizen-protectors" concludes, those who purchase guns for personal safety and self-defense do so with the idea of assisting law enforcement based on a sense of duty to others and absolutist belief in the right to self-defense.

Print media, however, is just one of the mediating forces that make up the marketing and advertising of guns. It is an assemblage of various human and non-human actants that includes graphic designers, copy editors, glossy paper, printing presses, drivers and vehicles to distribute the magazines, and the magazine subscribers who consume the images. But guns, like all products, are more likely to be advertised online through consumer blogs and review videos posted on social media sites like Facebook and YouTube. Here, advertising is an assemblage of computer monitors, servers, social media personalities, web cams, and algorithms that circulate these videos to interested parties. In these spaces, guns enthusiasts follow the self-defense script, but they can also push boundaries large gun corporations cannot, figuratively adding "color" to what participants in this community mean by "criminal." It reveals the internet not simply as a space brought into being by digital technology, but also by the legal infrastructure that divorces the foul opinions of internet users from the platforms that give those users a place to express themselves. The sheer amount of online content is overwhelming, with viewership that far exceeds print media and is unable to be fully cataloged in this essay, yet one example helps to illustrate this point.

John Correia's organization Active Self-Protection is one of the most popular YouTube channels for self-defense and also hosts a popular Facebook page and Twitter account for gun enthusiasts. Known as a calm and less hyperbolic gun advocate, his videos often feature the use of surveillance footage to explain various principles of self-defense. While Correia refrains from using explicitly racist and sexist language to narrate the footage, a large portion of the videos feature people of color and nearly a quarter of the videos are from Brazil. In the comments section, viewers are less restrained than Correia, using racially coded language like "thug" and "gangster" to define who is to be defended against. This becomes ever clearer when viewing the comments on his Facebook posts. Fans deploy more explicitly political and racialized language to attack gun control advocates, express praise for police, and reinforce what self-defense looks like. While Correia helps to mediate a more sanitized image of self-defense, it is not hard to come across racist and sexist memes that cast people of color, and increasingly immigrants, as threats. I make this point only to note (1) the highly racialized way in which web 2.0 intersects with gun culture 2.0, allowing gunowners a semiindependent voice that shapes firearm demand, (2) how these less regulated spaces make more apparent the racialized idea of selfdefense being communicated to gunowners and communicated amongst gunowners. Finally, it underscores the broader advertising infrastructure brought about by the internet and social media platforms that together form the assemblage of marketing and advertising that mediate what good self-defense looks like.

Carlson (2015) points out that even the black concealed carry permit holders she met in Michigan thought of their guns as protecting them from crime. But within communities of color self-defense is not simply articulated as defense against criminals, but defense against racist whites and abusive police. This fear of white violence is well warranted given the continued history of police violence against communities of color, the latitude police currently possess to abuse their power, and the way white violence against communities of color occurs with impunity. This fear of the state is not all that different from the fear white gunowners express towards a government they believe is ready to take their weapons and encroach on their rights. Yet, in the digital spaces where self-defense is imagined, cops are often praised while potential gun regulators, the IRS, and other facets of the state are viewed with suspicion. The standoff that took place in Oregon when militias affiliated with the Sovereign Citizens Movement took over the Malheur National Wildlife Refuge is one example of a long list of instances in which whites took up arms to protest the state. The standoff ended with one person shot dead after he tried to pull his gun on an officer, another was wounded, but the majority of armed assailants made it out alive and most received probation or short prison sentences. Comparing this to the countless unarmed men of color shot dead by police, online commentary from black, Latino, and Muslim Americans pointed out how this form of armed protest found acceptance from whites and was met with patience and understanding by law enforcement. Writing for The Root, Richard Prince (2016) detailed the degree to which commentators of color immediately pointed out the contradiction in the government's reaction, contrasting the events in Oregon with the way the government responds to people of color engaged in armed protest against aggressive and incessant police violence. 
Returning to Appadurai, the point here is not to weigh the legitimacy of either claim to revolt, but to demonstrate how demands for self-defense entail the construction of what selfdefense means, who has access to it, and under what circumstances. There are practical reasons why a gunmaker would not want to promote and advertise citizens arming themselves against police no matter the strength of their political claim, but there are similarly practical reasons why you would not want citizens arming themselves to prevent crime, crime that already appears on the decline despite gun ownership remaining steady (Ingraham, 2016).

Yet gun advertising does not act alone. Motivated by this narrower understanding of self-defense, gun rights advocates succeeded across the United States in loosening gun ownership restrictions and expanding concealed carry protections (Osnos, 2016; Medlock, 2005). Beginning in the late 1970s, the NRA spearheaded efforts to pass concealed carry permit legislation across the country which shifted firearm demand to smaller, semi-automatic pistols and revolvers (Reich and Barth, 2017). These efforts were later accompanied by legislative pushes for open-carry, stand your ground laws that expanded self-defense doctrine, and most recently no-permit carry legislation (Light, 2017). Federal gun control legislation like the Assault Weapons Ban was allowed to lapse, efforts are underway for a national concealed carry law, and Supreme Court precedents set in District of Columbia v. Heller (2006) and McDonald v. Chicago (2010), ruled that implied in the second amendment was an individual's right to possess a weapon, in that case a handgun, for the purpose of self-defense. And in 2005, Congress passed the Protection of Lawful Commerce in Arms Act, a bill that immunized gun manufacturers, dealers, and distributers from civil liability for damages caused by guns.

Law as a mediant is itself an assemblage of judges, lawyers, lawmakers, police officers, paperwork, administrative offices and courthouses, certification documents, finger printing technology, various processes for collecting and evaluating evidence, and a range of other human and non-human actants. Their contribution to the loosening of gun restrictions gave self-defense legal form, though unevenly. Concealed carry permit approval rates are lower for people of color and laws that prohibit those with a felony record from possessing a weapon disproportionately affect people of color who have been the targets of racist policing and an unfair criminal justice system (Newton, 2017). States with some of the loosest gun laws coincidentally possess some of the strictest penalties for unlawful possession of a firearm or for committing a crime with a firearm-laws enforced more harshly against people of color. Stand your ground statutes also follow this pattern, with whites able to claim self-defense under these provisions at higher rates than other groups (Associated Press, 2014). Finally, even when people of color lawfully possess their weapon, in practice their rights are suspect and their gun places them in greater danger as Philando Castile's death tragically revealed (Karim, 2016). While the intentions of some gun control advocates are laudable, they ignore how these laws intersect with existing white privilege and place greater burdens on the ability of people of color to exercise their second amendment rights. At the same time, it reaffirms the idea pushed by the NRA and others that the harm caused from guns is due to irresponsible ownership that must be punished individually rather than viewed as a logical outcome of a country inundated with firearms and where their specific use is encouraged by various social actors and endorsed by politicians and courts.

Finally, self-defense is the material outcome of changes in gun design and engineering. Gunmakers now devote considerable investment to producing handguns that are easier to conceal and meant for self-defense (Squires, 2019). In engineering terms, this means that pistols are now lighter, more accurate, capable of shooting higher caliber bullets, and are outfitted with a range of accessories that enhance the weapon's killing power. Gun consumers are cognizant of these changes and in response many discipline themselves for gun ownership and concealed carry, using both the skills they receive from the numerous courses offered by the NRA and other organizations, and the embodied knowledge they accumulate over time with their gun (Shapira and Simon, 2018; Carlson, 2015). In general terms, the aim is for gun owners to become comfortable with their weapon and its potential power, while constantly encouraging the gun owner to stay vigilant of potential threats to their personal safety. Many overlook the ways in which the materiality of guns affects gun owners psychologically. If advocates for gun regulation view gun owners as obsessed with their firearms, they miss vital considerations of gun design, thus leaving gunmakers free of scrutiny.

Racialized appeals to self-defense create a material assemblage of human, gun, bullet, and relevant handgun accessories. Selfdefense is the active outcome of one drawing their weapon and using it on a potential threat, the legal outcome of being found to have acted in self-defense, or in most cases it an idle-state in which the gunowner is ever-ready to defend themselves. It is in this sense that one might say that the gun becomes a mediant, a filter that turns certain humans into threats to be defended against. This is not a psychological aberration, but an embodied effect that comes from routine practice with handguns (Shapira and Simon, 2018). Web-based 2.0-gun culture is awash with videos on how to detect such a threat and how to respond to it with one's firearm. Yet, as noted earlier, that sense of threat is always racialized through the way self-defense is imagined via marketing and advertising of guns, making guns a key actant not only in the harm they can cause to others, but also in the assemblage of white identity, understood not just as being phenotypically white, but as accessing a particular kind of privilegeafforded investment in whiteness (Lipsitz, 1998). This particular white identity borrows from an inherited, racialized past that links to the present through the purchase and use of firearms. Conceived this way, white identity is not a singular thing, but an assemblage of a number of mediations at work depending on the context (Hartigan, 2005). Over the past decades, guns became a cornerstone of a particular kind of white masculinity, but it is not the only kind. Whiteness, in this sense, is the freedom to choose, a limitless set of permutations emerging out of commodity relations that are both systemic and deeply personal and intersect with lines of difference like class and gender.

Appadurai's approach to objects clarifies how demand for guns is not simply a top-down manipulation of gun consumers by gun makers but is instead a much more vibrant field of contestation in which the meaning of guns is multiple. Attention to race allows us to see how even the concept of self-defense as narrowly understood within popular gun culture is already racialized, marginalizing the self-defense claims of communities of color against white supremacy and the deep history of African Americans, Native Americans, and Latino Americans using their guns to defend themselves against these forces. But guns are not inert objects that simply channel the desires of their users. Their use over time shapes those desires which in turn influences both the demand for guns and the production of certain kinds of guns. The harms guns cause in American life are no different than just about anything else, they are disproportionately experienced by people of color. We miss this systemic reality when we focus on gun ownership as an individual activity or gun violence as an individual problem. Embedded in all of this is the question of politics, which cuts in multiple and contradictory directions that leave open the space for change and surprise. Mainstream politics pathologize black and brown gun ownership, but in another 
arena, they also pathologize white gun ownership, turning mainstream gun culture into a community that feels marginalized and under siege. States that have expanded gun rights have continued a deeply rooted historical legacy of tying the gun to white privilege, something made apparent during George Zimmerman's trial. However, my argument is not that gunowners think of their weapons as providing them white privilege-relations of privilege are never that apparent-but rather that the demand for self-defense masks those relations of privilege and normalizes how we think about guns, the harms guns cause, and how that harm should be distributed. To illustrate this point, in the next section I turn to the Trayvon Martin murder and Zimmerman trial by following Zimmerman's gun.

\section{The possessive investment in guns}

In May 2016, George Zimmerman successfully auctioned the handgun he used to murder Trayvon Martin. The auction was the third attempt by Zimmerman to sell the weapon and according to reports, Zimmerman made nearly a quarter million dollars from the sale. The website that hosted the auction, United Gun Group, functions as an online marketplace for individuals wishing to sell their firearms and a forum for gun enthusiasts. After concluding the auction, Zimmerman promised to donate the proceeds from the sale to supporting gun rights advocacy organizations and to fighting Hillary Clinton's "anti-gun rhetoric," a statement that explicitly drew links between Zimmerman's remorseless slaying of Martin and the entitlements he believed were granted to him under the Second Amendment.

The auction was not the first time Zimmerman went to the public for financial assistance and support. Shortly after he was charged with Martin's murder, Zimmerman created a website that solicited donations for his litigation costs during the trial period (Fausset, 2012). As he claimed both during and after the trial, the attacks against him were part of a racist witch-hunt, and an attempt to delegitimize and undermine guns rights successes like "Stand Your Ground." His appeal for help attracted a throng of supporters nationwide and garnered the attention of leading guns rights organizations, with the NRA even using Zimmerman's trial to publicly state that self-defense was a "fundamental human right." With the coordinated support of the gun rights community, Zimmerman managed to spin the story and turn himself into a victim, staking the outcome of the trial as a matter of human rights-for gun owners. Zimmerman's overwhelmingly white and conservative supporters quickly pointed out Zimmerman's half-Latino identity as evidence the incident was not about race, but Zimmerman's investment in his gun and his claim of self-defense granted him access to whiteness (Lipsitz, 1998). As Lipsitz (1998) points out, individuals and communities of color strategically invest in whiteness which often entails working with whites to deploy the forces of racism against another racial group - usually Black Americans. While the public debated whether Zimmerman was a racist, Zimmerman focused on his gun, using it to connect himself to the privileges of gun ownership that simultaneously sought to paint Martin as a threat to safety, replaying a now routine American story in which the white vigilante emerges as a redeemable figure (Light, 2017). More recently, Zimmerman extended this sense of entitlement in a lawsuit against Martin's family, their lawyer, and the state of Florida, demanding \$100 million for what the suit alleges was an unfair prosecution (Lee, 2019).

Zimmerman and Martin's encounter should be viewed as a specific material outcome of self-defense, one brought into being through the mediating forces of advertising and marketing of guns, Florida laws around gun possession and self-defense, and the specific gun Zimmerman carried that evening.
In 1987, Florida became a concealed carry state, allowing license holders to possess a handgun on their person and concealed from view. Over the years, changes to Florida's concealed carry resulted in an incredibly high number of permit holders with more than 700,000 active permit holders in Florida at the moment. From 1987 to the present, a deeply embedded gun culture grew in Florida, with one investigation showing that the average Florida resident lived within 10 miles of a gun dealer, and that there are 3.2 times the number of gun dealers in Florida than post offices. Gun enthusiasts consider Florida's concealed carry permit system exemplary, with 28 other states replicating Florida's laws. The concealed carry provisions sit together with other gun regulations that make it easy for anyone in Florida to possess a weapon, including allowing the private sale of firearms without a background check, no waiting period for gun purchases, and a statewide regulation that prohibits local municipalities from implementing gun regulations stricter than state law. Regulations that do exist place rules on the kind of gun one is able to possess, with state laws banning the sale of machine guns and excluding "long guns" (rifles, shotguns, etc.) from concealed carry permits. The result is a regulatory environment and gun market skewed towards self-defense.

The maker of Zimmerman's weapon, Kel-Tec, is an American gun manufacturer based in Cocoa, Florida, about an hour southeast of Sanford, where Zimmerman shot Martin. In the spirit of tasteless publicity stunts, Zimmerman visited the company before his trial, taking a tour of the premises and even shooting a shotgun. According to gun enthusiasts, Kel-Tec is known for designing lightweight pistols for the express purpose of concealed carry, a move that put the company in the top five American gun manufacturers. When Zimmerman confronted Martin, he carried with him a Kel-Tec PF-9, a weapon Kel-Tec claims is the lightest and flattest $9 \mathrm{~mm}$ pistol ever mass-produced (Longstreet, 2011). Described as a hybrid model, its design improves on the earlier P-11 and P-3AT models and is meant as a concealed sidearm for law enforcement and personal self-defense (Tom, 2014). Guns \& Ammo Magazine reviewer Payton Miller (2013) described the PF9 as," a pretty good example of newbreed, chopped-down $9 \mathrm{~mm}$ "pocket pistols" capable of easy concealment and maximum harm. According to the PF-9 manual, the gun's lightness and its power come from the design of its hammer, which allows the weapon to fire at incredibly high velocities for the gun's size (about the size of a man's hand).

But guns in Florida have not been distributed evenly. This is due to what Chase and Williams (2014) point out as the result of unevenly enforced laws that routinely punish black and brown individuals for gun possession. As they note, the concealed carry movement and the loosening of gun regulations in Florida also paralleled tough on crime measures that created new and harsher penalties for those who committed a crime with a firearm (Chase and Williams, 2014). The claim of self-defense, they note, is more accessible to whites, especially when the victim is a person of color (Ackermann et al., 2015). The story of Marissa Alexander, an African American woman from Jacksonville, makes this point devastatingly clear (Chase and Williams, 2014). After years of dealing with an abusive partner, in 2010 Alexander fired a warning shot after her husband threatened her with violence. In 2012, Alexander was sentenced to 20 years in prison after a Florida judge rejected her claim of immunity under Florida's Stand Your Ground provision, instead using the state's mandatory minimum for gun related crimes to dole out the long, harsh sentence. Alexander, of course, was not the poster child of the gun rights movement, nor was she able to count on the NRA and others for moral and financial support-despite her more compelling story as a survivor of domestic abuse. Unlike Zimmerman, Alexander's race and gender precluded her from accessing the 
privileges of whiteness afforded to others who possess a weapon, it was instead her use of a gun that triggered her violation of the prevailing racial code, thus making her possession of a weapon recognizable and punishable by the state (Light, 2017).

Zimmerman's gun afforded him such privilege, or to put it differently, his claim of self-defense was a material outcome mediated, in part, by his weapon. His decision to fire his weapon and kill Martin may have been influenced by his belief that the law would protect him, but the fact he could walk around his neighborhood with a concealed pistol on his person is also an outcome of legal, political, and economic forces that give form to the demand for self-defense. But Zimmerman's gun also darkened Martin, mediating Martin as a dangerous and troublesome youth and thus the object of Zimmerman's self-defense claim. The black male, John Eskow (2014) reminds us, attracts the suspicion of whites, his mere stare the sight of white panic. Yet, in the context of decades of gun marketing and racist political dog whistles about crime, Zimmerman's gun heightened that panic-a substitute for the de jure segregation that once did the work of policing the gated neighborhood where Martin was murdered. It might be obvious that Zimmerman's gun afforded the possibility of an incident of gun violence, but what is less obvious are the forces at work that make Martin's death and the thousands of others like it a common occurrence.

Without the gun, one wonders whether Zimmerman would have ignored the 911 operator's instructions, whether instead a story of racial gun violence may have become a story of racist police harassment, or perhaps, just nothing at all. And then again one wonders if the suspicion and fear Zimmerman invoked was his from the start-that it did not come prepackaged with the PF-9 he purchased beforehand, or that it was not cultivated over time as Zimmerman learned to use his gun and invest in the whiteness the gun offered. Whiteness resists its destruction by pretending to be nothing at all, by escaping view and thus settling into the normalcy of everyday life. It is not just the shooting, but the fact whites can possess a gun in the first place and carry that gun freely without suspicion or scrutiny. It is, as Tamir Rice's story disturbingly cautions, a privilege not afforded to black and brown Americans even when the gun they possess is a toy, or more hauntingly, even when the thing they possess is a cell phone or wallet. The phantom gun associated with black men and used as a justification for police and civilian shootings of people of color, illustrate the force of racism in constructing our ideas not just of who the "bad" and "good" guys are, but our assumptions as to who is in possession of a weapon. The white owner's gun, then, becomes swept up in a mediating process whose material outcome is not just murder, but the phantom gun black men are assumed to possess, the gun's other.

\section{Conclusion}

The possessive investment (Lipsitz, 1998) in the gun occurs at multiple registers and cannot be understood outside of their demand. But demand, Appadurai insists, is neither singular nor constant and it is this fact that should bring hope to those concerned with the harm guns cause. Shifting gun demand to selfdefense, however, has produced obvious social effects which only become clear as one follows the social life of the gun and traces the way its demand is shaped by a range of social forces and distinct social actors. Demand is always a site of contestation in which multiple meanings compete for power and in the American context, the meaning of guns must be understood as a site of racial politics that, when closely analyzed, allows for a more refined comprehension of how gun demand varies across different racial groups.
More contemporary anthropological approaches to objects requires attending to the way objects can mediate our sense of reality and produce physical effects that go beyond their mere symbolism. Appadurai's earlier theory anticipated this move when he spoke of the way changes in demand might change the object itself (1986), but his later work asks us to think about this relationship as a two-way street. Gun research now wades into this space, focusing on the way gunowners embody their guns, the cognitive effects of gun ownership, and of course the unique harms guns cause. The demand for self-defense is a material outcome of a number of mediating processes at work, processes shaped by the reproduction of inequality and constitutive of it as well. While guns remain central to the reproduction of whiteness from colonial America until the present moment, this paper does not argue that such constancy was ever guaranteed or is inevitable. In our current moment, guns are a material outcome of racialized demands for self-defense, but guns have become a mediant, intersecting with other mediants, of race itself, whitening certain kinds of gunowners while darkening others. This is not just true of those who possess guns, but those who are the victims of gun violence as the question of who is and is not a legitimate victim is in part mediated by the gun.

Among the many fears gun rights advocates worry about, perhaps we can frame their concern about their weapons being taken away not simply as a rhetorical plea in the service of America's culture wars, but as a material fear that threatens to upend their white identity and their sense of self (Carlson, 2015). In the same vein, we might begin to view gun manufacturers not only as "merchants of death," but as builders in what we routinely refer to as the social construction of race. In making this move we could shift away from conceiving race as a given, as an already available and coherent construction, and instead as a coconstituted set of relations between people, places, objects, and events. For Saldanha $(2012,2015)$, what emerges from this perspective is the shedding off of a discrete set of racial categories, triggering the opening of limitless racial possibilities, of the chance to let race be more than a marker of stratification and oppression. But the opportunity for race to become something else is not as easy as shifting demand or taking objects seriously. As the gun demonstrates, objects can represent a paradox for people of color when both their possession and dispossession leave them vulnerable to racial violence. Where the demand for self-defense might prove costly for people of color, for whites, this essay suggests that moving demand away from self-defense might hold more promise than a rehashing of legal debates over the legitimacy of the second amendment.

Shifting gun demand away from self-defense is likely to occur through campaigns less directly related to gun control. Placing overt legal restrictions on gunowners is likely to meet stiff resistance since it will reaffirm the calculus gunowners make between their right to gun possession and personal safety, and the harms gun cause. It will also probably lead to more incarceration of people of color. The more radical elements of the criminal justice reform movement offer an alternative approach that may have more success. These movements aim to reduce incarceration and police abuse but remind Americans that tough on crime policies do not make them safer, undermine civil liberties, are extremely expensive, and often can exacerbate crime. Fear is another material outcome bundled in the demand for self-defense, but it is a fear whose power can be neutralized as more localities move forward with progressive criminal justice reform. By reframing what personal safety and crime reduction looks like (a complex process of mediation), these groups demand that money be spent on education, housing, and healthcare over policing, prisons, and guns. Their aim, then, is not to pass laws that make it harder to arrest and jail people, but instead to insist on laws that regulate 
guns to make them safer (smart guns), tax gun manufactures, and hold gun makers and sellers liable for the harm their products cause in the US and abroad. Underlying these efforts is the call that we confront the damage done through the normalization of tough on crime policies and the integration of carceral logics into all parts of social life. These efforts may seem futile in light of recent efforts to arm teachers in response to school shootings, but they should offer us hope as the meaning of guns, like all objects, is subject to change.

\section{Data availability}

All data generated or analyzed during this study are included in this published article.

Received: 27 June 2019; Accepted: 14 April 2020;

Published online: 04 May 2020

\section{Notes}

1 It should also be noted that whites tend to own multiple firearms rather than a single gun for home defense.

\section{References}

Ackermann N et al. (2015) Race, law, and health: Examination of stand your ground and defendant convictions in Florida. Soc Sci Med 142:194-201

Ahmed S (2007) A phenomenology of whiteness. Feminist Theory 8(2):149-168

Aistrup JA (1996) The southern strategy revisited: republican top-down advancement in the south. University Press of Kentucky, Lexington

Appadurai A (1986) The social life of things: commodities in cultural perspective. Cambridge University Press, Cambridge

Appadurai A (2015) Mediants, materiality, normativity. Public Cult 27 (2):221-2371

Associated Press (2014) Stand-your-ground gun laws 'benefit whites more than blacks', experts say. https://www.theguardian.com/us-news/2014/oct/17/ stand-your-ground-white-black-gun-law-harm-fear. Accessed 20 Apr 2019

Bennett J (2010) Vibrant matter: a political ecology of things. Duke University Press, Durham

Bonilla-Silva E (2006) Racism without racists: color blind racism and the persistence of racial inequality in America. Rowman \& Littlefield Publishers, Lanham

Borneman J (2015) Cruel attachments: the ritual rehab of child molesters in Germany. University of Chicago Press, Chicago

Bureau of Justice Statistics (2011) Household burglary 1994-2011. https://www.bjs. gov/index.cfm?ty=pbdetail\&iid=4657. Accessed 20 Apr 2019

Carlson J (2015) Citizen-protectors: the everyday politics of guns in an age of decline. Oxford University Press, New York

Chase R, Williams Y (2014) Gun laws and race in America. In: Grey Kevin Alexander, Clair Jeffrey St, Wypjiewski Jo Ann (eds) Killing Trayvon: an anthology of American violence. CounterPunch Books, Petrolia

Cornell S, DeDino N (2004) A well regulated right: the early American origins of gun control. Fordham Law Rev 73(2):487-528

Cramer CE (1994) The racist roots of gun control. Kans J Public Policy 4(17):17-26

Durban-Ortiz R (2018) Loaded: a disarming history of the second amendment. Open Light Books, San Francisco

Eskow J (2014) Who's afraid of black men's eyes. In: Grey KA, Clair JSt, Wypjiewski JoAnn (eds) Killing Trayvon: an anthology of American violence. CounterPunch Books, Petrolia

Fagan J, Wilkinson DL (1998) Guns, youth violence, and social identity in inner cities. Crime and Justice 24:105-188

Fausset R (2012) Trayvon Martin Case: George Zimmerman website solicits donations. The Los Angeles Times. https://www.latimes.com/nation/la-xpm2012-apr-10-la-na-nn-zimmerman-website-20120410-story.html. Accessed 26 Apr 2020

Haag P (2016) The gunning of America: business and the making of American gun culture. Basic Books, New York

Hartigan J Jr (2005) Odd tribes: toward a cultural analysis of White people. Duke University Press, Durham

Hirschman EC (2003) Men, dogs, guns, and cars: the semiotics of rugged individualism. J Advertising 32(1):9-22

Houtman D, Meyer B (2012) Things: religion and the question of materiality. Fordham University Press, New York
Ingraham C (2016) American gun ownership drops to lowest in nearly 40 years Washington Post. https://www.washingtonpost.com/news/wonk/wp/2016/ 06/29/american-gun-ownership-is-now-at-a-30-year-low/. Accessed $20 \mathrm{Apr}$ 2019

Karim Z (2016) Black Americans and the Paradox of Concealed Carry Laws. Ebony https://www.ebony.com/news/gun-rights-black-people/. Accessed 20 Apr 2019

LaPierre WR (2003) Guns, freedom, and terrorism. WND Books, Nashville

Latour B (2005) Reassembling the social: an introduction to actor-network-theory. Oxford University Press, New York

Lee M (2019) Trayvon Martin's killer has a financial grievance. Atlantic https:// www.theatlantic.com/ideas/archive/2019/12/trayvon-martins-killer-hasfinancial-grievance/603319/. Accessed 15 Jan 2020

Light C (2017) Stand your ground: America's love affair with lethal self-defense. Beacon Press, Boston

Lipsitz G (1998) The possessive investment in whiteness: how whites profit from identity politics. Temple University Press, Philadelphia

Longstreet C (2011) Gun review (take three): Kel-Tec PF9. Truth About Guns. http://www.thetruthaboutguns.com/2011/01/caleb-longstreet/gun-reviewtake-three-kel-tec-pf9/. Accessed 20 Apr 2019

McIntosh P (1988) White privilege: Unpacking the Invisible Knapsack. The National Seed Project. https://nationalseedproject.org/Key-SEED-Texts/ white-privilege-unpacking-the-invisible-knapsack. Accessed 20 Apr 2019

Medlock S (2005) NRA=no rational argument-how the Nation Rifle Association exploits public irrationality. Tex J Civ Lib Civ Rights 1(1):39-64

Metzl J (2019) Dying of Whiteness: How the politics of racial resentment is killing America's heartland. Basic Books, New York

Miller P (2013) Kel-Tec PF-9 review. Guns Ammo. http://www.gunsandammo. com/reviews/kel-tec-pf-9-review/\#ixzz4UvQUPhh2. Accessed 20 Apr 2019

Montoya MJ (2007) Bioethnic conscription: genes, race, and Mexicana/o ethnicity in diabetes research. Cult Anthropol 22(1):94-128

Morin R (2014) The demographics and politics of gun owning households. http:// www.pewresearch.org/fact-tank/2014/07/15/the-demographics-and-politicsof-gun-owning-households/. Accessed 20 Apr 2019

Murphy J (2018) Are "Stand Your Ground" Laws racist and sexist? A statistical analysis of cases in Florida, 2005-2013. Soc Sci Q 99(1):439-452

Newton C (2017) Gun control's racist past and present. Al Jazeera. https://www. aljazeera.com/indepth/features/2017/10/gun-control-racist-present171006135904199. Accessed 20 Apr 2019

O'Brien K et al. (2013) Racism, gun ownership and gun control: biased attitudes in US Whites may influence policy decisions. PLoS ONE 8(10):e7552

O'Neill KL (2007) Armed citizens and the stories they tell: the National Rifle Association's achievement of terror and masculinity. Men Masc 9(4):457-475

Osnos E (2016) Making a killing: the business and politics of selling guns. New Yorker. https://www.newyorker.com/magazine/2016/06/27/after-orlandoexamining-the-gun-business. Accessed 20 Apr 2019

Parham-Payne W (2014) The role of the media in the disparate response to gun violence in America. J Black Stud 45(8):752-768

Pitts L Jr (2016) George Zimmerman takes a victory lap over Trayvon Martin's grave. Miami Herald. https://www.miamiherald.com/opinion/opn-columnsblogs/leonard-pitts-jr/article78242467.html. Accessed 20 Apr 2019

Prince R (2016) Commentators say ore. Government takeover would not have lasted 3 weeks if militants weren't white. The Root. https://journalisms. theroot.com/commentators-say-ore-government-takeover-would-not-hav1790887755. Accessed 20 Apr 2019

Ralph L (2014) Renegade dreams: living through injury in Gnagland Chicago. University of Chicago Press, Chicago

Reich G, Barth J (2017) Planting in fertile soil: The National Rifle Association and state firearms legislation. Soc Sci Q 98(2):485-499

Saldanha A (2006) Reontologising race: the machinic geography of phenotype. Environ Plan D 24(1):9-24

Saldanha A (2012) Assemblage, materiality, race, capital. Dialogues Hum Geogr 2 (2):194-197

Saldanha A (2015) Scale, difference and universality in the study of race. Postcolon Stud 18(3):326-335

Saylor EA et al. (2004) Firearm advertising: product depiction in consumer gun magazines. Eval Rev 28(5):420-433

Shapira H, Simon SJ (2018) Learning to need a gun. Qual Sociol 41(1):1-20

Silverman DJ (2016) Thundersticks. Harvard University Press, Cambridge

Slotkin R (1985) The fatal environment: the myth of the frontier in the age of industrialization, 1800-1890. Anthereum Press, New York

Smith AT (2015) The political machine: assembling sovereignty in the bronze age Caucasus. Princeton University Press, Princeton

Spitzer RJ (2005) Gun control: constitutional mandate or myth? In: Tatalovich R, Daynes BW (eds) Moral controversies in American politics, 3rd edn. M.E. Sharpe, Armonk

Spitzer RJ (2017) Gun Law history in the United States and Second Amendment Rights. Law Contemp Probl 80(2):55-83 
Squires P (1996) Deadly technology in the Post Industrial Society: a case study of firearms and firearms control. In: Karamjit GS (ed) Information society. Springer, London, pp. 304-329

Squires P (2019) Semi-automatics for the people? The marketing of a new kind of man. In: Carlson J, Goss KA, Shapira H (eds) Gun studies: interdisciplinary approaches to politics, policy, and practice. Routledge, New York, pp. 40-66

Swanson JW et al. (2015) Guns, impulsive angry behavior, and mental disorders: results from the National Comorbidity Survey Replication (NCS-R). Behav Sci Law 33(2-3):199-212

Tom R (2014) Gun review: Kel-Tec PF-9. http://www.thefirearmblog.com/blog/ 2014/03/05/gun-review-kel-tec-pf-9/. Accessed 20 Apr 2019

Witkowski TH (2013) The visual politics of US gun culture. In: Belk RW, Price L, Peñaloza L (eds) Consumer culture theory: research in consumer behavior. Emerald Group Publishing Limited, Bingley, pp. 3-23

Witt JK, Brockmole JR (2012) Action alters object identification: wielding a gun increases the bias to see guns. J Exp Psychol: Hum Percept Perform 38 (5):1159-1167

Yamane D et al. (2009) The rise of self-defense in gun advertising. In: Carlson J, Goss KA, Shapira H (eds) Gun studies: interdisciplinary approaches to politics, policy, and practice. Routledge, New York, pp. 19-39

\section{Acknowledgements}

I would like to acknowledge Jesse Rumsey-Merlan and EB Saldaña for their proofreading assistance and editorial support as well as thank Prof. Serguei A. Oushakine and Prof. Wendy Belcher for their important comments and suggestions on earlier drafts of this manuscript.

\section{Competing interests}

The author declares no competing interests.

\section{Additional information}

Correspondence and requests for materials should be addressed to B.H.-P.

Reprints and permission information is available at http://www.nature.com/reprints

Publisher's note Springer Nature remains neutral with regard to jurisdictional claims in published maps and institutional affiliations.

\section{(c) (1)}

Open Access This article is licensed under a Creative Commons Attribution 4.0 International License, which permits use, sharing, adaptation, distribution and reproduction in any medium or format, as long as you give appropriate credit to the original author(s) and the source, provide a link to the Creative Commons license, and indicate if changes were made. The images or other third party material in this article are included in the article's Creative Commons license, unless indicated otherwise in a credit line to the material. If material is not included in the article's Creative Commons license and your intended use is not permitted by statutory regulation or exceeds the permitted use, you will need to obtain permission directly from the copyright holder. To view a copy of this license, visit http://creativecommons.org/ licenses/by/4.0/.

(C) The Author(s) 2020 